Recepción: 20 / 04 / 2017

Aceptación: 20 / 05 / 2017

Publicación: 15 / 09 / 2017

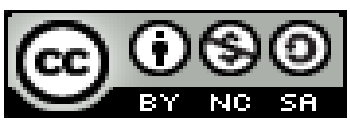

Ciencias de la salud

Artículo Científico

\title{
El tabaquismo y sus consecuencias para la salud periodontal
}

\section{Smoking and its consequences for periodontal health}

\section{Tabagismo e suas conseqüências para a saúde periodontal}

Juan A. Oliveira del Rio ${ }^{\mathrm{I}}$ janoliveira.12@yahoo.com

Alba M. Mendoza-Castro II alba.12mendo@gmail.com

Zully A. Macías-Velásquez ${ }^{\mathrm{III}}$ zullymacias1.@gmail.com

Correspondencia: editor@polodelconocimiento.com

I Docente de la Universidad Laica Eloy Alfaro de Manabí, Manta, Ecuador.

II Docente de la Universidad Laica Eloy Alfaro de Manabí, Manta, Ecuador.

III Odontóloga, Universidad Laica Eloy Alfaro de Manabí, Manta, Ecuador. 


\title{
Resumen
}

El tabaquismo es considerado uno de los mayores problemas de salud pública del mundo, según la Organización Mundial de la Salud. Se sabe que fumar interfiere en diferentes formas sobre la salud del tejido de la cavidad bucal, está directamente relacionado con problemas de salud bucal, el mismo tiene un efecto tóxico en el periodonto, A tal efecto se realizó una cuidadosa revisión de la literatura en los artículos científicos publicados en los últimos diez años. En el presente trabajo se ofrecen algunas consideraciones acerca de la relación existente entre el tabaquismo y la morbilidad periodonto.

Palabras claves: Tabaquismo; periodonto; enfermedad periodontal; terapia periodontal; tabaco.

\begin{abstract}
Smoking is considered one of the biggest public health problems in the world, according to the World Health Organization. It is known that smoking interferes in different ways on the health of the tissue of the oral cavity, is directly related to oral health problems, it has a toxic effect in the periodontium. For this purpose, a careful review of the literature in the scientific articles published in the last ten years. In the present work some considerations about the relationship between smoking and periodontal morbidity are offered.
\end{abstract}

Key words: Smoking; periodontium; periodontal disease; periodontal therapy; tobacco. 


\section{Introducción.}

La cavidad bucal se afecta en toda su extensión, y es ahí donde se produce el primer contacto con el tabaco, que trae como resultado efectos negativos como halitosis, manchas extrínsecas de dientes y restauraciones, abrasión de superficies dentales, caries dental, estomatitis nicotínica, estados preneoplásicos y enfermedad periodontal. ${ }^{1}$

El tabaquismo ha sido considerado un hábito, aunque ya en la actualidad lo encontramos clasificado como una enfermedad por sus efectos adictivos y dañinos a la salud. ${ }^{2}$

En todo el mundo, fuman en la actualidad alrededor de 1300 millones de personas. Esta cifra corresponde a $47,5 \%$ de los hombres y $10,3 \%$ de las mujeres. Como consecuencia la lista de enfermedades relacionadas con el tabaco tiende a aumentar y con ella la tasa de mortalidad. El tabaco es responsable de 1 de cada 10 muertes de personas adultas ( 5 millones de muertes cada año) y se cree que en el año de 2020 la cifra llegará a los10 millones al año ${ }^{2}$.

En una perspectiva, para el año 2030 fallecerán cerca de 8 millones de personas por año a causa del cigarro, preferentemente en países de bajo y mediano desarrollo ${ }^{3}$

El humo de cigarrillo es una compleja mezcla de cerca de 4.000 componentes con propiedades citotóxicas, mutagénicas y carcinogénicas dentro de los cuales se encuentran acetaldehído y acroleína (irritantes de la vía aérea), naftamalina, pireno, cadmio, benzopireno, dibenzacridina, uretano y toluidina (sustancias cancerígenas) y muchas otras sustancias tóxicas para el organismo, siendo de las más estudiadas la nicotina, debido a su relación con la adicción de los pacientes 4 
La inhalación pasiva o activa produce una disolución de los productos de la combustión en el epitelio oral y la vía aérea. Estos productos de combustión pueden dividirse en gaseosos y particulados, siendo este último tipo de partícula la que concentra la mayor toxicidad ${ }^{4}$.

El humo de cigarro como tal daña directamente las células epiteliales orales induciendo producción de quimiocinas y liberación de mediadores inflamatorios . ${ }^{4}$

Palmer ${ }^{5-4}$ ha concluido que los efectos deletéreos del tabaco en el ámbito sistémico son por exposición y absorción en los pulmones, más que por la absorción en la cavidad oral.

\section{Desarrollo.}

El tabaquismo se asocia más frecuentemente al progreso de periodontopatías inflamatorias e influye de un modo trascendental en la evolución y el pronóstico de la enfermedad periodontal. En el mundo existe una alta incidencia de personas fumadoras que, generalmente, inician el hábito desde edades muy tempranas, especialmente en la adolescencia y la adultez temprana, y presentan con prontitud los efectos del tabaco en las encías. La morbilidad por enfermedad periodontal se incrementa con el aumento de la exposición a la nociva práctica: a mayor cantidad de cigarros diarios y más tiempo de consumo, más grave será la afección. ${ }^{6}$

Entendemos por periodontitis, a la inflamación de los tejidos de sostén de los dientes con progresiva destrucción ósea y pérdida del ligamento periodontal. ${ }^{4}$

La periodontitis es una enfermedad inflamatoria iniciada por la acción de microorganismos presentes en el biofilm dentogingival y que lleva a la destrucción del aparato de inserción 
periodontal. Uno de los principales factores de riesgo para el desarrollo de periodontitis es el hábito de fumar ${ }^{4}$

Se le ha asociado al aumento de placa bacteriana, pérdida de hueso alveolar, formación de bolsas periodontales y pérdida de órganos dentarios. ${ }^{4}$

El tabaquismo no solo incrementa el riesgo de desarrollo de periodontitis, sino que también afecta de manera muy significativa a la respuesta a la terapia periodontal tanto quirúrgica como no quirúrgica. $^{4}$

Efecto sobre los tejidos periodontales.

Una de las primeras alteraciones periodontales es la recesión gingival y la hiperplasia epitelial. Entre el 25-30\% de los fumadores presenta recesión gingival. Por otro lado, en fumadores se han detectado niveles altos de mediadores inflamatorios como interleucina-1 y prostaglandina E2 que pueden inducir leucoplasias, llamada hiperplasia gingival ${ }^{4}$.

Cuando el individuo cesa de fumar, la mayoría de las zonas con estas lesiones blancas de la mucosa tienden a revertirse. Estudios en militares indican que este tipo de lesiones producidas por tabaco se revierten en 6 semanas en el 97\% de los fumadores ${ }^{4}$.

En ese mismo sentido los fumadores presentan menor inflamación gingival y menor sangrado al sondaje que los no fumadores. La supresión de desarrollo normal de la inflamación asociada con la provocación de la placa bacteriana se sugiere que es debido a los productos del humo del tabaco que interfieren con la respuesta inflamatoria vascular. El sangrado reducido en los fumadores se ha atribuido a la vasoconstricción gingival inducido por las acciones de la nicotina la 
cual estimula la adrenalina y la noradrenalina se ha evidenciado que la nicotina influye en la expresión del HIF-1a (Factor Inducible de Hipoxia 1a) ${ }^{8}$

La nicotina se une a la superficie radicular en los fumadores y puede inhibir el crecimiento de los fibroblastos derivados del ligamento periodontal, alterar su fijación, la expresión de la integrina y la producción de colágeno. Los radicales libres en los tejidos periodontales se incrementan en los fumadores en comparación con los no fumadores los cuales también pueden dar a los fibroblastos del tejido. Los fibroblastos con discapacidad por causa del tabaquismo conducen al retraso en la reparación de tejidos y cicatrización de heridas en la enfermedad periodontal. ${ }^{7}$

El tabaquismo aumenta la severidad de la enfermedad periodontal haciéndose clínicamente evidente este efecto a partir de 10 cigarrillos por día. Cada cigarrillo extra al día aumenta la recesión gingival, la profundidad de bolsa, los niveles de inserción y la movilidad. La severidad de la enfermedad periodontal y la cantidad de cigarrillos fumados al día, tiene una relación dosisrespuesta. $^{8}$

\section{Características del paciente fumador.}

El fumador con periodontitis presenta características clínicas diferentes de las del no fumador. Estos signos clínicos pueden enmascarar la enfermedad periodontal si no se realiza una correcta evaluación. Los pacientes se caracterizan por enfermedad periodontal más generalizada, tejido gingival fibrótico o hiperqueratósico con márgenes gruesos, mínimo enrojecimiento y edema, mayor pérdida de inserción periodontal en dientes anteriores con mayor tamaño de la palatina anterior, menor sangrado al sondaje, mayor recesión gingival en molares superiores por palatino y en elementos anteroinferiores, mayor pérdida de hueso y de dientes. Los fumadores presentan una cantidad superior de piezas dentarias con afectación de furcas, profundidad de bolsa e 
hipermovilidad. En sujetos de entre 20 y 45 años existe una asociación de prevalencia de periodontitis y tabaquismo. Por otra parte, el progreso de la enfermedad periodontal medido en pérdida de inserción es superior en los fumadores $(0.19 \mathrm{~mm}$ por año) que en los no fumadores $(0.10$ mm por año). La pérdida ósea es de 3 a 5 veces más rápida en los primeros. Además, los fumadores de más de 20 unidades diarias comprometen considerablemente cualquier tratamiento. ${ }^{9}$

Según Traviesa Herrera ${ }^{1}$ en su investigación el $100 \%$ de los pacientes examinados la higiene bucal de los fumadores se encontró muy comprometida, al aparecer predominio del cálculo en una mayor extensión. La intensidad del tabaquismo a medida que aumenta reporta mayores daños en la higiene bucal, así como en el estado periodontal.

En otra investigación realizada por Traviesa Herrera ${ }^{10}$ obtuvieron como resultado una prevalencia de la enfermedad periodontal en el $100 \%$ de los pacientes examinados fumadores, no así en la población no fumadora.

Otros autores ${ }^{8}$ obtuvieron como resultado una prevalencia de la enfermedad periodontal en el $100 \%$ de los pacientes examinados fumadores, no así en la población no fumadora.

Se concluye que los fumadores, $\mathrm{y}$ en especial los que fuman grandes cantidades de cigarrillos, tienen la tendencia de padecer enfermedad periodontal por el efecto local de los productos derivados de la combustión, y el efecto general por los productos tóxicos del tabaco sobre el organismo.

\section{Referencias bibliográfica.}

1- Traviesas Herrera Eladio Miguel, Rodríguez Llanes Ricardo. Tabaquismo, higiene bucal y periodontopatías inmunoinflamatorias crónicas en adultos del municipio Guanajay. Rev 
Cubana Estomatol . 2007 [citado 2017 Oct 31] ; 44( 1 ): . Disponible en: http://scielo.sld.cu/scielo.php?script $=$ sci arttext\&pid=S0034-75072007000100005\&Ing $=$ es

2- Lordelo M.J.. El tabaco y su influencia en el periodonto. Avances en Periodoncia . 2005 [citado 2017 Oct 28] ; 17( 1 ): 17-24. Disponible en: http://scielo.isciii.es/scielo.php?script=sci_arttext\&pid=S1699-65852005000100003\&lng=es.

3- World Health Organization. Report on the global tobacco epidemic, 2011

4 Rojas Javier Patricio, Rojas LA, Hidalgo R. Tabaquismo y su efecto en los tejidos periodontales. Rev. Clin. Periodoncia Implantol. Rehabil. Oral . 2014 [citado 2017 Oct 28]

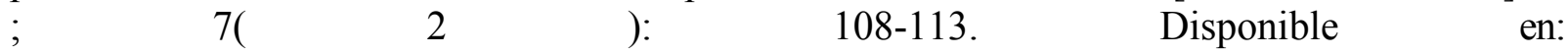
http://www.scielo.cl/scielo.php?script=sci_arttext\&pid=S071901072014000200010\&lng=es. http://dx.doi.org/10.4067/S0719-01072014000200010

5- Palmer RM, Wilson RF, Hasan AS, Scott DA. Mechanisms of action of environmental factors-tobacco smoking. J Clin Periodontol 2005;32 Suppl 6:180-95

6- Pérez Barrero Bernardo Ricardo, Sánchez Zapata Rosario, Gondín Gener Milagros, Sánchez Garrido Ana Victoria, Gan Cardero Bárbara. Periodontal status of patients attended in Vista

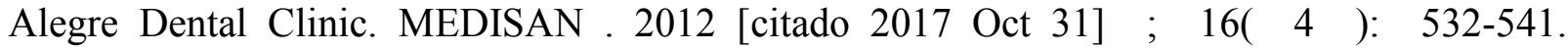
Disponible en: $\quad$ http://scielo.sld.cu/scielo.php?script=sci arttext\&pid=S1029$\underline{30192012000400007 \& \operatorname{lng}=\text { es. }}$.

7- Cid, C. F. , Soto, N. B. Efectos del Tabaquismo en la Microbiota y Tejido Periodontal: Revisi.n de la Literatura. Int. J. Med. Surg. Sci., 3(2):855-862, 2016.

8- Bolaños Cruz S, Torres Medina C , González Cruz H Osio Echanove, Díaz Romero R . Frecuencia de enfermedad periodontal y reabsorción ósea alveolar en pacientes con adicción al tabaco en el Instituto Nacional de Enfermedades Respiratorias. 2008. . LXV( 2) pp 75-80

9- Fernández Bodereau E, Tortolini P . El Hábito de Fumar y los Tejidos Periodontales. Revista de la Asociación Odontológica Argentina 91(1):18-22, 2003. [citado 2017 Oct 28]. Disponible en: http://www.bago.com/BagoArg/Biblio/infecto235web.htm

10- Traviesas Herrera Eladio Miguel, Seoane Larrinaga Ana Mary. Prevalencia y gravedad de las periodontopatías en adultos jóvenes del municipio Artemisa en relación con la práctica del tabaquismo. Rev Cubana Estomatol . 2007 [citado 2017 Oct 31] ; 44( 2 ): . Disponible en: http://scielo.sld.cu/scielo.php?script=sci arttext\&pid=S0034-75072007000200003\&lng=es. 